\title{
Políticas públicas e Capital social: \\ o Projeto Consultório de RuA ${ }^{\star}$
}

Maria Eniana Araújo Gomes Pacheco $\star \star$ Universidade Estadual do Ceará, Fortaleza, CE, Brasil

\section{RESUMO}

Discute-se nesse ensaio questões pertinentes a sociedade moderna, na perspectiva de Bauman e Giddens, com um recorte para a temática das drogas. Reflete-se o Projeto Consultório de Rua enquanto um equipamento das políticas de saúde, com prática social inclusiva à população em situação de rua, no Brasil. Analisam-se as categorias, capital social e habitus, enquanto temáticas transversais na prática dos profissionais do Projeto Consultório de Rua, através do aporte teórico em Pierre Bourdieu. Por conseguinte, pretende-se, a partir dessa discussão, contribuir com as diferentes práticas dos profissionais na área da saúde, no tocante ao uso e abuso de substâncias psicoativas.

Palavras-chave: redução de danos; saúde mental; inclusão; projeto consultório de rua.

\section{Public Policy and CAPITAl SOCIAL: the Projeto Consultório de RuA}

\begin{abstract}
We discuss in this article relevant issues in modern society, from the perspective of Bauman and Giddens, with a cutout for the issue of drugs. Reflected in the Projeto Consultório de Rua as a product of health policies with social practice inclusive of the homeless population in Brazil. It examines the categories, capital and habitus, as transversal themes in professional practice Projeto Consultório de Rua, through the theoretical Pierre Bourdieu. In consequence, the goal is to contribute to this discussion from the different practices of professionals in health, regarding the use and abuse of psychoactive substances.
\end{abstract}

Keywords: harm reduction; mental health; inclusion; projeto consultório de rua.

^Estudo sob o financiamento da Fundação Cearense de Apoio ao Desenvolvimento Científico e Tecnológico - FUNCAP.

$\star \star$ Endereço para correspondência: Faculdade Juazeiro do Norte - Curso de Arquitetura. Rua São Francisco, 1224 - São Miguel, Juazeiro do Norte - CE, 63010-210. Juazeiro do Norte, CE Brasil.E-mail: enianaagp@yahoo.com.br 


\section{INTRODUÇÃo}

Atualmente, no Brasil, as questões pertinentes ao uso e abuso de drogas no âmbito das políticas públicas inclusivas, na esfera da saúde, buscam por ações integrais durante práticas terapêuticas.

A prática terapêutica na saúde pública brasileira é orientada e ofertada à população pelo Sistema Único de Saúde (SUS), considerado a maior política de inclusão social do País, que possui como diretrizes os princípios doutrinários da universalidade, ${ }^{1}$ integralidade ${ }^{2}$ e o princípio ético da equidade, ${ }^{3}$ cuja forma de organização e operacionalização apoiam-se na participação popular, na regionalização e hierarquização, na descentralização ${ }^{4}$ e no comando único ${ }^{5}$ (BRASIL, 1990).

O SUS agrega à prática em saúde conhecimentos sobre meio físico - por intermédio das condições geográficas, água, alimentação, habitação; meios socioeconômico e cultural - incorporando o emprego, renda, educação, hábitos; e a promoção, proteção e recuperação da saúde (BRASIL, 2004a).

Entre as políticas públicas nacionais destinadas ao combate do uso e abuso de substâncias psicotrópicas, as iniciativas estatais e os projetos voltados à prevenção e promoção da saúde e tratamento das enfermidades são orientados pelos princípios do SUS, que preconizam a humanização dos serviços e a articulação entre os diferentes equipamentos sociais (BRASIL, 2004b).

Em meio a estas iniciativas estatais e projetos, em 2009 o Ministério da Saúde selecionou Projetos de Consultório de Rua que fossem vinculados às secretarias municipais dos diferentes estados brasileiros com o fim de desenvolver ações destinadas a usuários de drogas em situação de rua. Foram selecionados 14 municípios $^{6}$ para executarem abordagem de rua com usuários de substâncias psicoativas por meio das intervenções clínicas, psicossociais e educativas (BRASIL, 2010b).

O Consultório de Rua é um dispositivo para além do modelo biomédico, que se distancia da lógica de demanda espontânea e abordagem única voltada à abstinência, caracterizando-se fundamentalmente por oferecer cuidados no próprio espaço da rua, respeitando o contexto sociocultural da população (BRASIL, 2010c; OLIVEIRA, 2009).

Esse dispositivo também é citado pelo Centro Brasileiro de Informações sobre Drogas Psicotrópicas (CEBRID) como um projeto caracterizado pela participação ativa de profissionais da saúde junto à população de rua sem que seja desrespeitado o seu contexto social. Na prática desse projeto, composto por uma equipe multidisciplinar se procura assegurar a integralidade da assistência atuando sob uma perspectiva interdisciplinar do cuidado em saúde ao indivíduo (BRASIL, 2010c).

O Consultório de Rua tem como princípios norteadores o respeito às diferenças, a promoção de direitos humanos e inclusão social, o enfrentamento a estigmas, ações em redução de danos e intersetorialidade mediante as ações integrais aos usuários do SUS (BRASIL, 2010c; OLIVEIRA, 2009). 
A busca por ações integrais teve seu movimento originado, no Brasil, na década de 70 , através de uma normalização que prevê oportunidades iguais, apesar das diferenças, aos sujeitos, entre as políticas públicas, ofertando condição favorável à inclusão dentro dos processos comunitários de territorialidade (GOFFREDO, 1997).

A integração ao perpassar pela educação, saúde, trabalho, cultura, lazer e atividade física, por todos os cidadãos, sofre normalização pelo Estado e é conceituada como um processo dinâmico de participação das pessoas num contexto relacional, legitimando sua interação nos grupos sociais que implica a reciprocidade (BRASIL, 2006). Contudo, ressalta-se que o modelo integrativo oferece barreiras quando não há uma participação ativa da sociedade.

O cenário para a participação ativa dessa sociedade moderna oferece entraves ao ser caracterizado, por Bauman (2001) como pertencente a um tempo instantâneo, com realização e satisfação imediata, desengajamento, descorporificação do trabalho humano, emergência do software, acúmulo de capital extraterritorial, volátil, inconstante e de curtos prazos.

Em relação à participação ativa débil da sociedade, na luta por interesses variados de grupos específicos, o autor, aponta reflexições a partir da:

desintegração da rede social, a derrocada das agências efetivas de ação coletiva, é recebida muitas vezes com grande ansiedade e lamentada como "efeito colateral" não previsto da nova leveza e fluidez do poder cada vez mais móvel, escorregadio, evasivo e fugitivo. Mas a desintegração social é tanto uma condição quanto um resultado da nova técnica do poder, que tem como ferramentas principais o desengajamento e a arte da fuga. Para o poder [...] qualquer rede densa de laços sociais, e em particular uma que esteja territorialmente enraizada, é um obstáculo a ser eliminado. Os poderes globais se inclinam a desmantelar tais redes em proveito de sua contínua e crescente fluidez. E são esse derrocar, a fragilidade, o quebradiço, o imediato dos laços e redes humanos que permitem que esses poderes operem (BAUMAN, 2001, p. 15-16).

Acerca dessa mobilidade social, na organização atual da sociedade, Giddens (1991), também discorre sobre os riscos e incertezas que a caracterizam, acrescentando a necessidade por uma nova teoria social que contemple o complexo da sociedade contemporânea:

Se formos compreender adequadamente a natureza da modernidade, quero argumentar, temos que romper com as perspectivas sociológicas [...] Temos que dar conta do extremo dinamismo e do escopo globalizante das instituições modernas e explicar a natureza de suas descontinuidades em relação às culturas tradicionais. (GIDDENS, 1991, p. 25). 
Assim, Giddens (1991) concorda com o caráter apócrifo e acidental da modernidade, ainda definindo-a como "estilo, costume de vida ou organização social que emergiram na Europa a partir do século XVII [...] e tornaram mais ou menos mundiais em sua influência" (GIDDENS, 1991, p. 11).

Para o autor há uma radicalização da modernidade, em que o modo de vida iniciado no século XVII chegou ao seu ápice, promovendo como conseqüências as incertezas manufaturadas e a reflexividade.

O autor acrescenta que a questão dinâmica do tempo-espaço sofre metamorfoses no âmbito da modernidade, em todas as esferas sociais, devido as novas tecnologias de comunicação virtual, característica dos processos de globalização. Nessas condições é que Giddens (1991) irá definir a globalização como uma ação à distância, geradora de transformações no âmbito social e político.

Em conformidade com Giddens (1991), Bauman (2001) acrescenta à modernidade a fluidez, caracterizada por sua mobilidade e inconstância, correlacionando-a com a dinâmica inconstante da relação entre tempo-espaço, nos processos de globalização, informando:

A modernidade começa quando o espaço e o tempo são separados da prática da vida e entre si, e assim podem ser teorizados como categorias distintas e mutuamente independentes da estratégia e da ação [...] O tempo adquire história uma vez que a velocidade do movimento através do espaço se torna uma questão do engenho, da imaginação e da capacidade humana (BAUMAN, 2001, p. 15-16).

Essa estrutura global de mobilidade fluida, por fim, se constitui em ferramenta de poder e dominação, na sociedade moderna (BAUMAN, 2001).

Nesse cenário é que transita, na sociedade moderna, as políticas públicas inclusivas brasileiras, acomodando-se aos princípios básicos de universalidade, equidade e integralidade, do Sistema Único de Saúde (BRASIL, 2008).

Diante do interesse pelo estudo do Projeto Consultório de Rua enquanto um dispositivo clínico-social no atendimento a usuário de drogas, em situação de rua, foca-se no princípio da integralidade devido a sua articulação em rede com os outros equipamentos sociais.

A integralidade, enquanto princípio do SUS, propõe uma comunicação eficiente entre os níveis de atenção a saúde, de forma a cuidar do indivíduo como um todo, em que se reconhece um sujeito inserido no contexto socioeconômico e cultural, na medida em que se trabalha o conceito saúde não só como ausência de doença (BRASIL, 2006).

Atualmente, na atenção de cuidados à saúde, se prioriza a integralidade enquanto um processo de construção dos espaços de troca e pactuação entre os profissionais entre si e os usuários, implantando normas e protocolos dentro do sistema de saúde, possibilitando que o indivíduo percorra diferentes níveis de atenção, de acordo com sua necessidade (FERREIRA, 2009). 
O FENÔMENO DROGAS NA CONTEMPORANEIDAdE E AS POLÍTICAS PÚBLICAS DE

\section{INCLUSÃO NA SAÚDE MENTAL}

A questão emergente nas discussões entre os processos de inclusão e exclusão, na sociedade contemporânea brasileira, é o advento epidemiológico das drogas.

Para se refletir as questões referentes a dialética inclusão-exclusão, em espaços urbanos e rurais, convém ressaltarmos a relevância das discussões defendidas por Santos (2003), Sawaia (2007), Foucault (2004) e Marx (1993).

Santos (2003) ao discutir a cidade como lócus do crescimento e da inovação tecnológica, a apresenta como atraente para aqueles que buscam melhorar sua condição social. Isso acontece porque nesses espaços urbanos os serviços estão em maior quantidade e a lei da oferta e da procura crescem a fatores exponenciais. Paralelo a esse exponencial pode-se também observar o não acesso a esses diferentes e variados serviços, nos espaços urbanos, o que favorece a desigualdade e pobreza (SANTOS, 2003). Assim, por essa lógica, demarcada em um mesmo território, pode-se retratar a inclusão segundo uma óptica de exclusão, dentre as políticas públicas de práticas integracionistas.

Corroborando com Santos, Sawaia acrescenta que na dialética da exclusão/ inclusão, nos processos de globalização, "a sociedade exclui para incluir e esta transmutação é condição da ordem social desigual, o que implica o caráter ilusório da inclusão" (SAWAIA, 2007, p. 8).

Temos também em Foucault algumas contribuições referentes à exclusão como processo dialético da inclusão. $O$ autor considera que a inclusão social como processo de disciplinarização dos excluídos, ocorre enquanto um processo de controle social e manutenção da ordem na desigualdade social. Nessas circunstâncias, se concebe a exclusão como um movimento de luta pelo poder (FOUCAULT, 2004).

Nos trilhos das concepções de luta pelo poder, Marx (1993) trata a miséria e a servidão como alicerces da sobrevivência do sistema capitalista, como ideia central na dialética exclusão/inclusão. A sociedade permite a inclusão do trabalhador ao mesmo tempo em que o aliena de seu esforço vital. Nesse contexto de dialética exclusão/inclusão, a exclusão insere-se nas estratégias históricas de manutenção da ordem social: reconstituem-se as formas de desigualdades pela segregação, apartheid, guerras, misérias e violência legitimada.

Nesse panorama dialético de exclusão/inclusão, a questão das drogas segregara os progressos na ciência às mudanças sociais e guerras em favorecimento ao aumento do consumo de substâncias psicoativas entre os indivíduos. A droga assume, por essa configuração histórica, diferentes significados e variados modos de utilização, na diversidade das tradições socioculturais de muitas sociedades (MACRAE, 2001). 
Em destaque, na atualidade, tem-se o desenvolvimento dessas questões, no domínio das políticas públicas em saúde, para o Projeto Consultório de Rua (PCR), o Decreto $n^{\circ} 7.179$, de 20 de maio de 2010, intitulado Plano Integrado de Enfrentamento ao Crack e outras Drogas (Plano Crack) que sofreu alterações em 8 de dezembro de 2011 pelo decreto $n^{\circ}$ 7.637. (BRASIL, 2010d, 2011).

O Plano Crack tem como ação imediata no campo da saúde a ampliação das ações de prevenção, tratamento, assistência e reinserção social em regiões de grande vulnerabilidade à violência e ao uso de crack e outras drogas. Assim, esse plano promove ações de cuidado intersetoriais e integradas entre a saúde e a assistência social.

Ao PCR o Plano Crack, presidido pela Presidência da República (BRASIL, 2010d) prevê ações de inclusão quando: amplia o quantitativo de equipes, a fim de abranger maior área territorial; promove atendimento extramuros aos usuários de drogas em situação de extrema vulnerabilidade social e de não acesso a rede de serviços de saúde; e fortalece o exercício de direitos e cidadania ao vincular o usuário de drogas a rede de assistência integral.

A estrutura do serviço PCR constitui-se enquanto um dispositivo clínico-comunitário, com uma equipe volante mínima, multidisciplinar e constituída por profissionais da saúde mental, atenção básica, pelo menos um profissional da assistência social, sendo: médico, assistente social, psicólogo, outros profissionais de nível superior, redutores de danos, técnicos de enfermagem e educadores sociais (BRASIL, 2010d).

Ainda sobre propostas inclusivas, o Plano Crack expedido pela Presidência da República (BRASIL, 2010d), sob a Coordenação Nacional de Saúde Mental, pelo Ministério da Saúde, prevê Casas de Acolhimento Transitório (CAT) do SUS, além dos Centros de Atenção Psicossociais, em articulação com a Atenção Básica. Essas CAT permitem abrigamento temporário, acolhimento e proteção social, em espaços da saúde, no contexto de um Projeto Terapêutico Individualizado desenvolvido pelos Centros de Atenção Psicossocial, em articulação com a Atenção Básica e com dispositivos intersetoriais (saúde, assistência social, direitos humanos, justiça, educação, e outros).

Esses equipamentos sociais integrados promovem ações de prevenção, promoção e integralidade no cuidado aos usuários de drogas, na contemporaneidade. Integralidade que admite políticas e serviços prioritários ao atendimento em rede, através do processo de diálogo entre profissionais com competências às referências e contrarreferências no atendimento à usuários do serviço público (BRASIL, 2008, 2010a).

Contudo, paralelo a essas medidas integrativas, com um recorte da política pública em saúde intitulada Plano Crack (BRASIL, 2011), está prevista a internação compulsória aos usuários de drogas em situação de extrema vulnerabilidade social.

Nessa proposta, que força uma internação a dependentes químicos em situação de vulnerabilidade, objetivando tratamento, observa-se uma perversa estratégia de exclusão $\mathrm{Na}$ internação involuntária não se disponibiliza ao sujeito a participa- 
ção na discussão de seu próprio atendimento, ação que impossibilita o cuidado em saúde mental enquanto instigador da autonomia e corresponsabilização do usuário no seu tratamento. Tem-se, então, nesse ato uma abordagem higienista de recolhimento dos usuários de drogas em situação de extrema vulnerabilidade social.

Além disso com o Plano Crack (BRASIL, 2011), observa-se a inclusão das comunidades terapêuticas como dispositivos do Sistema Único de Saúde.

Essas comunidades são instituições privadas que segregam, em um território demarcado, usuários de drogas sob a lógica da abstinência e execução de trabalho braçal, isolando o indivíduo das suas relações sociais, familiares e do seu processo de territorialidade cultural. Assim, por esse fato se pode questionar o retorno à lógica manicomial de internação involuntária em Hospitais Psiquiátricos, em sua maioria privatizados, no período entre os séculos XIX e XX.

Desse modo, essas medidas no âmbito da saúde podem ser dialogadas pela lógica da dialética exclusão/inclusão ao promoverem medidas de ampliação dos serviços, objetivando princípios de universalidade e integralidade, ao mesmo tempo em que mostra-se contrária a política de redução de danos que prioriza os princípios de equidade pelo respeito à sexualidade, às crenças e integração sociocultural, sempre tendo como meta a autonomia do indivíduo.

\section{O CAPITAL SOCIAL E O Habitus NO PROJETO CONSULTÓRIO DE RUA: POSSIBILIDADES E DESAFIOS}

Ao conceber que as interações entre o Projeto Consultório de Rua e sociedade sofrem mediações culturais e sociais, discute-se as categorias capital social e habitus a partir dos subsídios teóricos em Pierre Bourdieu. (1983, 1996, 2001, 2005, 2007).

Bourdieu (1983) substitui a noção de sociedade por campo ou espaço social, em que se prescrevem os seus próprios valores, independentemente da consciência e do desejo individual, e princípios objetivos de regulação.

Bourdieu (2007) aprofunda questões referentes à capital social ao abordar discussões a partir das análises relacionais entre indivíduo, sociedade e natureza. Essas análises relacionais que acontecem no habitus equivalem à integração das experiências passadas, informando ao processo institucional suas percepções, apreciações e ações.

A lógica própria dos relacionamentos delimitados no campo social constitui o habitus, refletida por Bourdieu (2001), que sofre influências pelo tipo das posições sociais no campo frente às regras práticas de ação, reproduzindo estruturas sociais na ação.

Em meio ao processo institucional no habitus, possibilita-se a realização de tarefas diferentes pela transferência analógica de esquemas, produzindo práticas que tendem a reproduzir as regularidades (BOURDIEU, 1983, 1996, 2007). No Projeto Consultório de Rua, os profissionais imergem sobre essas práticas regulares diárias que denunciam os processos inter-relacionais dos sujeitos, a partir de um cotidiano social, permeado por demarcações territoriais dinâmicas subjetivas de indivíduos em situação de rua. 
Pierre Bourdieu $(1996,2007)$ trouxe, com a noção de habitus, o entendimento de como as estruturas sociais, dentro de determinadas condições sociais e históricas específicas, moldam os corpos dos indivíduos, inscrevendo-lhes valores, significados e regras de conduta. Nesse contexto, para o autor, as estruturas cognitivas, imersas em estruturas sociais, não são formas de consciência, mas disposições do corpo em que os agentes sociais, com capacidades criadoras, ativas e inventivas, constroem seu mundo social.

Nesse processo, os indivíduos ocupam no campo social, uma posição determinada pela sua origem de classe ou grupo social, podendo elaborar suas representações e ações pelo habitus, constituinte pelo senso prático da vida, através dos esquemas de percepção e apreciação. Esse campo social constitui-se pelo campo de forças e lutas em que se manifestam as relações de poder, constituídas por símbolos através de esquemas cognitivos, a partir de uma distribuição desigual, ou seja, um quantum social (BOURDIEU, 1996, 2005, 2007).

Acerca do campo social, Bourdieu (1983), afirma ser "uma estrutura que é o produto de sua história anterior e o princípio de sua história ulterior" (BOURDIEU, 1983, p. 7).

As polêmicas no interior do campo social, a partir das contribuições em Bourdieu (1983), favorecem uma mobilização na relação entre a participação civil e o Estado ao elaborar e avaliar políticas públicas oriundas das necessidades dialógicas dos sujeitos coletivos na sociedade moderna.

Nesse contexto, a temática das drogas se apropria das construções simbólicas, no campo social. O objeto drogas, com símbolos ou não, anunciado por significados funcionais, desperta sentimentos atrativos à ação humana o que a legitima. Esses significados hão de comportar os símbolos formados por uma teia que une as construções dos estereótipos e das identidades (BOURDIEU, 2005).

A discussão sob dominação simbólica no indivíduo é interpretada por Bourdieu (2005, p. 147):

quando os esquemas que ele (o dominado) põe em ação para se ver e para se avaliar, ou para ver e avaliar os dominantes (elevado/baixo, masculino/ feminino, branco/negro, etc.) resultam da incorporação de classificações, assim naturalizadas, de que seu ser social é produto.

Nas estruturas de dominação simbólica há desigualdades de poder entre as relações coletivas que ultrapassam a dimensão econômica, incluindo os sentidos que encarceram os indivíduos através das estruturas naturalizadas, representando a inter-relação entre habitus e capital social, ancorados sob uma consciência coletiva (BOURDIEU, 2005, 2007). 
Ainda sobre o poder simbólico, Bourdieu (2005) afirma que as estruturas de dominação podem ser alteradas por constituírem-se a partir de reproduções, ou seja, recriações dinâmicas objetivas e subjetivas, inviáveis à explicação racional do comportamento de indivíduos singulares.

Assim, com o autor em discussão, é possível estabelecer vínculos relacionais flexíveis, não autoritários, entre os indivíduos, em meio a uma rígida construção sócio-histórica.

No intento de um sujeito reflexivo, o Programa Consultório de Rua (PCR) insere-se nos diálogos, do campo da saúde, incorporando em sua práxis os conflitos existenciais advindos do espaço social, que no sentido epistemológico de Pierre Bourdieu (1983) representa o campo social.

O PCR ao inserir-se no campo social de disputa constante com outros atores e instituições, através das ações em integralidade, no âmbito da saúde, tem seu planejamento em interface com os saberes referentes às ciências sociais, medicina preventiva, saúde pública e coletiva, antropologia, dentre outros. Deste modo, a complexidade interna frente às ramificações das políticas públicas, em planejamentos e avaliações, conforma na prática do PCR, um grande campo de conhecimentos, com relações de poder, socialmente delimitadas a partir da correlação entre as forças historicamente estabelecidas.

A disputa de poder entre grupos, através de suas ideologias e propostas teóricas ou conceituais, entre indivíduos ou agentes, pressupõe uma apropriação de capitais sociais, simbólicos e econômicos. Frente a essa diversidade entre os agentes, estes ao incorporar as regras do campo social podem contestá-las ou mudá-las (BOURDIEU, 2005).

Nas políticas públicas, com base em Pierre Bourdieu (2005) temos a garantia das regras no campo social, entre os agentes, como condutores da elaboração de atitudes no âmbito econômico, social e institucional - ao se considerar os interesses presentes e futuros da sociedade.

O conceito de agente social, em Bourdieu (2005), pode ser constituído por uma pessoa, grupo ou organização, envolvida em alguma ação social. Esse agente social, possuidor de habitus no âmbito da política, pode produzir fatos viáveis à concretude de suas reivindicações.

Entre os agentes sociais, as relações construídas tendem a reproduzir a distribuição desigual de poder, a partir da posição social e econômica que disponham, demarcando, assim, os papéis e as distâncias sociais (BOURDIEU, 1983, 2005).

No Sistema Único de Saúde, através do Programa de Humanização, essa posição social e econômica, tende a ser rompida quando nas práticas em saúde se prioriza a ampliação das competências na relação com o tratar e cuidar, em que o profissional deve converter a sua dimensão econômica e técnica à dimensão relacional (BRASIL, 2006). 
Pierre Bourdieu (1983, p. 187) trabalha os limites da competência, ao afirmar:

Assim, onde havia um campo religioso distinto, há doravante uma transposição do mesmo. Não é por acaso que um grande número de clérigos se torna psicanalista, sociólogo, trabalhador social etc., exercendo novas formas de cura com um estatuto laico.

Os saberes resultantes das práticas em saúde e qualidade de vida podem traduzir as desigualdades sociais no campo do "capital cultural" que em Bourdieu (2007), é herdado inicialmente ao indivíduo através da família e escola.

Sob essa perspectiva, conforme Pacheco (2013), as vivências apreendidas durante a prática dos profissionais da equipe do Consultório de Rua variam ao serem considerados os usuários enquanto sujeitos singulares, contudo coletivos, que interagem uns com os outros, no ambiente urbano. Na pesquisa de campo observou-se que uma informação sobre determinada substância psicoativa ser melhor para a saúde que outra não sofre nenhum impacto na mudança do uso coletivo ao ser desconsiderado as condições financeiras e vivências anteriores do grupo. Há grupos de usuários etílicos que não têm interesse em reduzir a quantidade do uso ou mesmo a troca por outra substância devido à aquisição ser de menor custo financeiro e às experiências durante a interação entre estes proporcionarem maior prazer na estadia pelas ruas do que em ambiente doméstico familiar. Isso ocorre porque:

No Consultório de Rua ou em qualquer outro que você trabalha, você tem essa questão da informação coletiva, onde não só você tem o seu conhecimento, mas todo o grupo que possa repassar isso de forma clara (COLABORADOR 3).

Por intermédio das práticas dialógicas entre os diferentes grupos de moradores em situação de rua e a equipe do PCR, surgem as intervenções possíveis que reduzam os danos físicos e sociais oriundos do uso por usuários, das substâncias psicoativas.

As intervenções dos profissionais do PCR podem ocorrem a partir da coparticipação dos usuários em atendimento, respeitando-se os limites deflagrados por este frente às propostas viáveis para a realidade do contexto em que estão inseridos (PACHECO, 2013).

Essa compreensão e a atitude de respeito durante as intervenções na abordagem de rua foram observadas, segundo Pacheco (2013), pelas falas dos profissionais da equipe do PCR a seguir:

Você está acessando através dos diferentes saberes propostas de que você está concebendo junto com essa pessoa, a realidade de cultura, a realidade de espaço físico que ela mora, o contexto social que ela vive. (COLABORADOR 4). 
Muitas vezes eu penso de um modo, mas aquele sujeito, que eu estou fazendo a abordagem, já pensa de outra forma. Então, eu tenho que respeitar o direito e os limites que eu encontro na rua com o usuário. (COLABORADOR 1).

Os saberes que constituem a dinâmica de determinados grupos, envolvem o respeito ao tempo e à escolha destes em relação ao consumo das substâncias psicoativas pelos profissionais do PCR durante a abordagem de rua - isso sob a lógica da redução de danos. A abordagem de rua orientada por práticas terapêuticas requer o conhecimento de diálogos com linguagem própria (BRASIL, 2010c).

Acerca desses diálogos que constituem a dinâmica de determinados grupos, em Pacheco (2013) podemos ter falas que compõem parte do vocabulário dos moradores em situação de rua, usuários de substâncias psicoativas, como por exemplo: "Iracema", significando "muita fome", "pipoco", significando "alguém está pronto para atirar em você", "passar o rodo", significando "agredir fisicamente outro até a morte", "vamos para holanda", significando "reunião de um determinado grupo para o uso da maconha em lugar específico, como por exemplo, em um mesmo banco de praça", "pivete", significando "amigo, companheiro".

Trata-se de falas que podem ser conhecidas por profissional do PCR, com vistas à trajetória de sua experiência social, o habitus do "menino que tava metido no tráfico, que tinha certa parceria" e depois motivou-se a trabalhar no âmbito da saúde a partir da admiração pelo trabalho de alguns membros da família como "Findei fazendo um curso de auxiliar de enfermagem, porque eu achei tipo: minha mãe já era auxiliar de enfermagem, as minhas irmãs, primas" (PACHECO, 2013).

$\mathrm{Na}$ pretensão por inverter essa situação, tem-se na perspectiva reflexiva de Bourdieu (1983), que a aquisição do capital social, enquanto uma forma de inserção dos indivíduos, inseridos em rede através das relações sociais, promove condições estáveis ao indivíduo ou grupo quando:

os agentes sociais e os próprios dominados encontramse unidos no mundo social, mesmo no mais repugnante e revoltante, por uma relação de cumplicidade padecida que faz com que certos aspectos desse mundo estejam para além ou aquém do questionamento crítico. Por meio dessa relação obscura de adesão quase corporal é que se exercem os efeitos do poder simbólico (BOURDIEU, 2001, p. 60).

Portanto, Bourdieu $(1983,2007)$ concebe campo social como um ambiente de distintas e desiguais formas de poder, configurando um campo de forças e de lutas construídas pela ação de agentes que se enfrentam com meios e fins diferenciados. Cada campo há de desenvolver valores particulares com base em princípios de regulação próprios, que delimitam um espaço socialmente estruturado no qual os agentes lutam, dependendo das posições que ocupam no campo, seja para mudar, seja para preservar seus limites e forma. 
A abordagem sócio-histórica proposta por Pierre Bourdieu (1983) desempenha um papel fundamental na organização do mundo social, em que o capital social se agrega ao sentido da comunidade a partir dos laços estabelecidos entre os membros que a integram. Laços esses, com níveis de formalidade distintos, mas caracterizados por um conhecimento comum e sentimento de participação.

\section{Conclusão}

Discussões sob os contornos das atividades pautadas em processos globais fragmentados, inseridos em redes dinâmicas e fluxos contínuos, com maior concentração populacional nas áreas urbanas, sugerem novas concepção da inter-relação do indivíduo na sociedade contemporânea.

Entre essas novas concepções, na atualidade, têm-se as discussões em torno da problemática droga que vem aparentando associarem-se mais a aspectos socioculturais da contemporaneidade do que à natureza das substâncias em si, frente a evolução da sociedade, com seus conflitos e desequilíbrios.

Aos profissionais do Projeto Consultório de Rua vale ressaltar que na abordagem ao usuário de substância psicoativa deve-se levar em consideração a heterogeneidade dos modos de consumo, as razões, às crenças, os valores, os ritos, os estilos de vida e as visões de mundo que o sustentam.

Ressalta-se que nessa abordagem, as práticas, em função da análise de diferentes habitus no campo social, podem orientar as ações em saúde, ao seguirem-se as estratégias internas dos processos sócio-históricos de cada território.

Sob esses territórios, para se compreender o habitus de um indivíduo, é preciso analisar sua trajetória individual, ao mesmo tempo que a história do ambiente onde acontecem os processos relacionais.

Nessa compreensão desconstrói-se o lugar do saber particularizado, em que o consumo de drogas acontece, ao se valorizar o conhecimento da demanda que é atendida, ante as relações dialógicas. Assim, ao se reconhecer esses saberes dos usuários de substância psicoativa, estes passam a ser apreciados em seus aspectos biopsicossociais.

Aos profissionais do PCR, questões como a busca por parcerias, ações sociais, reelaboração da identidade, desmistificação do estigma da pobreza, combate à exclusão e conquista da cidadania, devem ser consideradas na perspectiva dos processos de inclusão social.

Convém acrescentar que nos processos de inclusão social, diferentes políticas públicas, no campo da saúde, na sociedade moderna, abrolham-se a partir das necessidades humanas no decorrer do seu desenvolvimento sócio-histórico, oportunizando aos agentes sociais a capacidade de subversão às normas vigentes de uma configuração social. 
Essa discussão não se esgota nesse ensaio, pois ainda há muitas observações a serem discutidas a partir dos diferentes saberes implicados em práticas profissionais humanizadas, diversas e transversalizadoras, dialogáveis sob as variadas ramificações que a sociedade moderna consagra, no âmbito da saúde.

\footnotetext{
Notas

${ }^{1}$ Saúde como direito de todos os indivíduos.

${ }^{2}$ Acesso a todos os serviços médicos como direito de todos. Fomento a ações e serviços preventivos, curativos e coletivos, articulados e contínuos, exigidos em todos os níveis de complexidade de assistência.

${ }^{3}$ Reconhecimento das diferentes necessidades da população por meio de ações governamentais diferenciadas.

${ }^{4}$ Transferência de ações do governo federal para o estadual ou municipal.

${ }^{5}$ Um único gestor comanda as políticas de saúde na rede assistencial de abrangência.

${ }^{6}$ Dentre as cidades destacam-se: Maceió/AL, Manaus/AM, Salvador/BA, Fortaleza/CE, Brasília/ DF, Uberlândia/MG, Belém/PA, João Pessoa/PB, Curitiba/PR, Recife/PE, Niterói/RJ, Rio de Janeiro/RJ, São Bernardo do Campo/SP, Guarulhos/SP. (BRASIL, 2010c).
} 


\section{REFERÊNCIAS}

BAUMAN, Z. Modernidade líquida. Tradução de Plínio Dentzien. Rio de Janeiro: J. Zahar, 2001.

BOURDIEU, P. Questões de sociologia. Rio de Janeiro: Marco Zero, 1983.

BOURDIEU, P. Razões práticas: sobre a teoria da ação. Campinas: Papirus, 1996.

BOURDIEU, P. A economia das trocas simbólicas. São Paulo: Perspectiva, 2001.

BOURDIEU, P. O poder simbólico. Rio de Janeiro: Bertrand Brasil, 2005.

BOURDIEU, P. A distinção: crítica social do julgamento. São Paulo: Edusp, 2007.

BRASIL. Ministério da Saúde. Lei $n^{\circ}$ 8.080, de 19 de setembro de 1990. Disponível em: <http://www.planalto.gov.br/ccivil_03/leis/18080.htm>. Acesso em: 12 fev. 2012.

BRASIL. Lei n. 10.216, de 6 de abril de 2001. Dispõe sobre a proteção e os direitos das pessoas portadoras de transtornos mentais e redireciona o modelo assistencial em saúde mental. In: BRASIL. Ministério da Saúde. SecretariaExecutiva. Secretaria de Atenção à Saúde. Legislação em saúde mental: 19902004. 4. ed. rev. e atual. Brasília: Ministério da Saúde, 2004a.

BRASIL. Ministério da Saúde. Secretaria Executiva. Secretaria de Atenção à Saúde. Coordenação Nacional DST/AIDS. A política do Ministério da Saúde para a atenção integral a usuários de álcool e outras drogas. 2. ed. Brasília: Ministério da Saúde, 2004b.

BRASIL. Ministério da Saúde, Secretaria de Atenção à Saúde, Departamento de Atenção Básica. Política Nacional da Atenção Básica. Série A. Normas e Manuais Técnicos. Série Pactos pela Saúde, v. 4, 2. ed., 1. reimpr. Brasília, DF: MS, 2006.

BRASIL. Política nacional para inclusão social da população em situação de rua. Brasília, 2008. Disponível em: <http://www2.mp.pr.gov.br/direitoshumanos/ docs/isad/prua/publ02.pdf>. Acesso em: 10 set. 2009.

BRASIL. Ministério da Saúde. SAS/DAPES. Coordenação Nacional de Saúde Mental. Consultórios de Rua do SUS. Material de trabalho para a II Oficina Nacional de Consultórios de Rua do SUS. Brasília: Ministério da Saúde/Convênio Escola Politécnica Joaquim Venâncio - FIOCRUZ, 2010a. 
BRASIL. Ministério da Saúde. Secretaria de Atenção à Saúde. Departamento de Ações Programáticas Estratégicas. Coordenação Geral de Saúde Mental, Álcool e Outras Drogas. II Chamada para Seleção de Projetos de Consultórios de Rua e Redução de Danos (PCR-II). Brasília: Ministério da Saúde, $2010 \mathrm{~b}$.

BRASIL. Ministério da Saúde. Coordenação Nacional de Saúde Mental. Consultórios de Rua do SUS. Material de trabalho para a II Oficina Nacional de Consultórios de Rua do SUS. Brasília: Ministério da Saúde/EPJN-FIOCRUZ, 2010c.

BRASIL. Presidência da República. Plano Integrado de Enfrentamento ao Crack e outras Drogas. Decreto n 7.179 , de 20 de maio de 2010d.

BRASIL. Presidência da República. Plano Integrado de Enfrentamento ao Crack e outras Drogas. Decreto n ${ }^{\circ}$ 7.637, de 08 de dezembro de 2011.

FERREIRA, S. C. (Org.). Gestão em saúde: contribuições para análise da integralidade. Rio de Janeiro: EPSJV, 2009.

FOUCAULT, M. Vigiar e Punir. Tradução de Raquel Ramalhete. Rio de Janeiro: Vozes, 2004.

GIDDENS, A. As consequências da modernidade. São Paulo: Unesp, 1991.

GOFFREDO, V. L. F. S. Integração ou segregação? Eis a questão! In: MANTOAN, M. T. E. A Integração de pessoas com deficiência: contribuições para uma reflexão sobre o tema. São Paulo: Memnon, 1997. p. 230-235.

MACRAE, E. Antropologia: aspectos sociais, culturais e ritualísticos. In: SEIBEL, S. D.; TOSCANO JR., A. Dependência de drogas. São Paulo: Atheneu, 2001. p. 25-34.

MARX, K. Trabalho Alienado. In: Manuscritos econômico-filosófico. Lisboa: Edições 70, 1993. Textos filosóficos.

OLIVEIRA, M. G. P. N. de. Consultório de rua: um relato de experiência. 2009. 146 f. Dissertação (Mestrado em Saúde Pública)-Universidade Federal da Bahia, Salvador, 2009.

PACHECO, M. E. A. G. Política de redução de danos a usuários de substâncias psicoativas: práticas terapêuticas no Projeto Consultório de Rua em Fortaleza, Ceará. 2013. 143f. Dissertação (Mestrado Acadêmico em Políticas Públicas e Sociedade) - Universidade Estadual do Ceará, Fortaleza, 2013.

SANTOS, L. G. Politizar as novas tecnologias. São Paulo: Editora 34, 2003. 
SAWAIA, B. Introdução: exclusão ou inclusão perversa? In: As artimanhas da exclusão: análise psicossocial e ética da desigualdade social. 7. ed. Petrópolis: Vozes, 2007. p. 07-13.

Recebido em: 01 de março de 2012 Aceito em: 26 de junho de 2013 